\title{
Relojes, relojes, relojes y el cambio de hora ¿Son los relojes internos espejos del reloj externo?
}

\author{
Clocks, Clocks, Clocks and Daylight-Saving Time. Do our internal clocks match the external \\ clock time?
}

\begin{abstract}
Dos veces al año, en otoño y primavera ajustamos nuestros relojes, pero ¿Cambiamos el tiempo interno? Actualmente, acabamos de sincronizar nuestros relojes externos al llamado horario de verano, adelantándolos en una hora en Chile Continental e Insular, con la excepción de Magallanes y la península Antártica. La segunda vez que hacemos esto es a fines de otoño, pero en forma opuesta, retrasándolos una hora. Se calcula que casi un cuarto de la población mundial se somete a estos ajustes horarios. Así, no somos los únicos descontentos con estos cambios. De hecho, en el hemisferio norte, los ciudadanos de la Unión Europea eligieron por amplia mayoría, NO cambiar sus relojes a la hora de invierno como era habitual en septiembre y en vez de ello mantener una hora fija (la hora de verano) todo el año. Nos preguntamos, ¿Por qué tanto revuelo frente a un pequeño ajuste horario de una hora que ocurre aproximadamente cada 6 meses? ¿Por qué la preferencia de los ciudadanos europeos por mantener un horario estable a lo largo del año? La respuesta es simple. El adelantar o atrasar el reloj una hora nos genera desajustes fisiológicos, que se expresan, en algunos, en accidentes y patologías serias; en otros, la mayoría, en malestares subjetivos por 1 a 2 semanas, similares a los del jet lag como trastornos y deprivación de sueño, fatiga, pérdida de atención, disminución del estado de alerta y de la motivación, entre otros, isin movernos de nuestra casa! De hecho, experimentamos jet lag social, que se define como la discrepancia entre nuestro tiempo interno, dado por nuestros relojes biológicos y el tiempo social, impuesto por nuestro reloj exógeno ${ }^{1}$. Es así, que se reportan aumento de accidentes de tráfico fatales ${ }^{2}$, efecto negativo en salud cardiovascular, infartos y accidentes vasculares ${ }^{3}$ en los días siguientes al cambio de hora. Más aún, en niños y adolescentes, se detectan efectos adversos sobre sueño y rendimiento escolar ${ }^{4}$. Un hecho notable, es el llamado del Parlamento Europeo, a la comunidad cientifica a realizar una evaluación en profundidad de la pregunta básica ¿Cómo los ajustes horarios estacionales afectan nuestros relojes endógenos? (citado en ${ }^{3}$ ). Esfuerzos en esta dirección se están iniciando en Chile ya que la Comisión de Salud del Senado se reunió en agosto para tratar la incidencia en la salud humana del cambio de horario, y decide poner un estudio de los Drs. Latorre y Ewart "en conocimiento del Ministerio de Salud, en el entendido de que en la regulación de esta materia debe tener un rol o al menos un punto de vista que hacer valer, de manera que en la decisión no intervenga exclusivamente el Ministerio de Energía"5.
\end{abstract}

\section{Los relojes endógenos y el sistema circadiano}

Un acontecimiento confiable y predecible en nuestras vidas y en la de todos los organismos que habitamos el planeta Tierra, es la alternancia del día y la noche producto de la rotación de este sobre su eje en casi $24 \mathrm{~h}$. Un segundo aspecto es la alternancia de las estaciones del año producto del viaje de nuestro planeta alrededor del sol. Todos los seres vivos poseemos relojes biológicos que permiten adaptaciones fisiológicas predictivas a estos cambios ambientales. Estos relojes biológicos son estables, se caracterizan por tener un periodo de casi un día ( $24 \mathrm{~h}$, circa dies) y se denominan relojes circadianos. Los relojes circadianos ajustan su período a 24-h con una señal ambiental, siendo la más importante el ciclo luz/oscuridad. En ausencia de esta señal, el reloj sigue oscilando y mantienen un periodo cercano a $24 \mathrm{~h}$. Una importante propiedad de estos relojes es que, como todo buen reloj, su período no se afecta por la temperatura. Las bases moleculares de todos los relojes biológicos son un sistema de retroalimentación transcripcional/traduccional de un conjunto de genes, aptamente denominados genes reloj, que llevaron a obtener el premio Nobel de Medicina en 2017 a Jeffrey C. Hall, Michael Rosbash y Michael W. Young. En mamíferos el sistema circadiano consta de un reloj maestro, el núcleo supraquiasmático (NSQ), que recibe directamente la información luz/oscuridad desde la 
retina a través del tracto retino-hipotalámico. Este reloj maestro comanda por vía nerviosa (sistema nervioso autónomo) y vía humoral (melatonina) a relojes periféricos ubicados en cada una de las células de nuestros distintos órganos (corazón, pulmón, glándula suprarrenal, timo, hígado, pineal) resultando en oscilaciones circadianas en el transcriptoma, proteoma y función celular con máximos ajustados a diferentes horas de día. Las funciones de salida de estos relojes a nivel del individuo son las oscilaciones periódicas cada 24 h que conocemos como ritmos circadianos: sueño/vigilia, alimentación/ayuno, hormonas plasmáticas, presión arterial, temperatura corporal, etc. Así, nuestros sistemas fisiológicos se preparan para estar activos y alertas al comenzar el dia y disminuir nuestra actividad y dormir al anochecer. La importante consecuencia de la función del sistema circadiano es producir un orden temporal interno de funciones fisiológicas acorde con los cambios día/noche. Este orden está presente incluso durante la vida fetal, en que señales maternas ordenan funciones fetales con la hora del día ${ }^{6}$. La desincronización con el ambiente perturba nuestro orden temporal interno causando malestar e incluso patologías ${ }^{3,7}$. Para finalizar y contestando la pregunta del título, los relojes internos tienen vida propia y se han desarrollado en millones de años de evolución, sincronizándose con señales externas, otorgándole al individuo una respuesta predictiva a los cambios exteriores, una forma de óptima adaptación al ambiente. Desgraciadamente, la vida moderna disocia ambiente y biología. El impacto del jet lag social impuesto por los ajustes horarios que hemos descrito es solo la punta del iceberg de situaciones extremas como son los turnos laborales y genera una preocupación a futuro dada por los efectos de estos turnos en los hijos de madres gestantes. ¡Nos queda mucho por aprender!

María J. Serón Ferré, PhD

Laboratorio Cronobiología Programa Fisiopatología, ICBM, Facultad de Medicina, Universidad de Chile. Email:mseronfe@gmail.com

\section{Bibliografía}

1.- KANTERMANN T, JUDA M, MERROW M, ROENNEBERG T. The human circadian clock's seasonal adjustment is disrupted by daylight saving time. Curr Biol 2007; 17: 1996-2000.

2.- PRATS-URIBE A, TOBÍAS A, PRIETO-ALHAMBRA D. Excess Risk of Fatal Road Traffic Accidents on the Day of Daylight Saving Time Change. Epidemiology 2018; 29: e44-5.

3.- MANFREDINI R, DE GIORGI A, ZUCCHI B, CAPPADONA R, SIGNANI F, KATSIKI N, et al Daylight saving time and myocardial infarction:should we be worried? A review of the evidence. European Review for Medical and Pharmacological Sciences 2018; 22: $750-5$.
4.- MEDINA D, EBBEN M, MILRAD S, ATKINSON B, KRIEGER AC. Adverse Effects of Daylight Saving Time on Adolescents' Sleep and Vigilance. J Clin Sleep Med. 2015 11:879-84.

5.- $\mathrm{http} / / \mathrm{www} \cdot$ senado.cl/appsenado/index.php?mo=comisi ones\&ac $=$ ficha\&id=95. Boletin 10305, 14/08/18.

6.- SERÓN-FERRÉ M, RICHTER HG, VALENZUELA GJ, TORRES-FARFAN C. Circadian Rhythms in the Fetus and Newborn: Significance of Interactions with Maternal Physiology and the Environment. In Prenatal and Postnatal Determinants of Development. Walker, David W. (Ed.), Springer, Series. Neuromethods 2016; 109: 147-65.

7.- ROENNEBERG T, ALLEBRANDT K V, MERROW M, VETTER C. Social jet lag and obesity. Curr Biol 2012; 22: 939-43. 